\title{
Administration of supplemental L-tyrosine with phenelzine: a clinical literature review
}

This article was published in the following Dove Press journal:

Clinical Pharmacology: Advances and Applications

22 July 2014

Number of times this article has been viewed

\author{
Marty Hinz' \\ Alvin Stein ${ }^{2}$ \\ Ted Cole ${ }^{3}$ \\ Patricia Ryan ${ }^{4}$ \\ 'Clinical Research, NeuroResearch \\ Clinics, Inc., Cape Coral, FL, USA \\ ${ }^{2}$ Stein Orthopedic Associates, \\ Plantation, FL, USA; ${ }^{3}$ Cole Center for \\ Healing, Cincinnati, OH, USA; ${ }^{4}$ Family \\ Wellness Center, Omaha, NE, USA
}

Correspondence: Marty Hinz NeuroResearch Clinic, Inc., 1008 Dolphin Dr, Cape Coral, FL 33904, USA

$\mathrm{Tel}+\mathrm{I} 2186262220$

Fax +I 2186261638

Email marty@hinzmd.com
Abstract: The subject of this literature review is the alleged relationship between L-tyrosine, phenelzine, and hypertensive crisis. Phenelzine $\left(\mathrm{Nardil}^{\circledR}\right)$ prescribing information notes: "The potentiation of sympathomimetic substances and related compounds by MAO inhibitors may result in hypertensive crises (see WARNINGS). Therefore, patients being treated with NARDIL should not take [...] L-tyrosine [...]". Interest in the scientific foundation of this claim was generated during routine patient care. A comprehensive literature search of Google Scholar and PubMed revealed no reported cases of hypertensive crisis associated with concomitant administration of L-tyrosine and phenelzine. Review of current US Food and Drug Administration nutritional guidelines relating to ongoing phenelzine studies reveals no mention and requires no consideration of L-tyrosine ingestion in combination with phenelzine. This paper is intended to provide an objective review of the science to then allow the reader to formulate the final opinion.

Keywords: hypertensive crisis, phenelzine, tyrosine, tyramine, stroke, phenelzine

\section{Introduction}

\section{L-Tyrosine}

L-Tyrosine is a normal component of protein foods. It is a neutral amino acid and the precursor of the catecholamines dopamine, norepinephrine, and epinephrine. "Animal studies indicate that systemic administration of tyrosine in pharmacological quantities can reduce physiological and behavioral decrements induced by highly stressful conditions."

\section{Phenelzine}

Nardil $^{\circledR}$ (phenelzine) (Pfizer, Inc., New York, NY, USA) is a potent inhibitor of monoamine oxidase (MAO). Phenelzine sulfate is a hydrazine derivative. It has a molecular weight of 234.27 and is chemically described as $\mathrm{C}_{8} \mathrm{H}_{12} \mathrm{~N}_{2} \cdot \mathrm{H}_{2} \mathrm{SO}_{4}$.

Phenelzine prescribing information specifically notes: "The potentiation of sympathomimetic substances and related compounds by MAO inhibitors may result in hypertensive crises (see WARNINGS). Therefore, patients being treated with NARDIL should not take sympathomimetic drugs [...] or related compounds (including methyldopa, L-dopa, L-tryptophan, L-tyrosine, and phenylalanine)."2 In humans, L-tyrosine is metabolized to tyramine, L-dopa, dopaquinone, and 3-iodo-L-tyrosine. The literature is clear that the problem of phenelzine-associated hypertension is due to concomitant administration with tyramine (not tyrosine). ${ }^{3}$ 


\section{Results}

\section{No cases of L-tyrosine-induced hypertensive crisis have been documented}

A comprehensive literature search of Google Scholar and PubMed revealed that the first phenelzine studies were published in $1959 .{ }^{4}$ There have been no documented cases of L-tyrosine-associated hypertensive crisis. Conversely, several articles were found illustrating that when normal blood pressure exists or the subject is hypertensive, L-tyrosine lowers blood pressure. ${ }^{4-12}$ The assertion that ingestion of L-tyrosine with phenelzine induces hypertensive crisis is without scientific literature verification.

When Google Scholar was searched for articles containing the exact phrase "L-tyrosine induced hypertensive crisis", no articles were found; however, the exact phrase "tyramine induced hypertensive crisis" identified 50 articles. PubMed is the recognized "gold standard" for peer-reviewed scientific publication certification. A search there using the query "L-tyrosine, phenelzine, hypertensive crisis" failed to reveal any peer-reviewed literature.

\section{Avoidance of all L-tyrosine is not possible}

Phenelzine prescribing information advises against tyrosine ingestion. It makes no recommendations regarding the level of L-tyrosine restriction. The only specific food restriction guidelines are for foods high in tyramine. ${ }^{2}$

With L-tyrosine found in virtually all protein foods, the prescribing information poses a confounding problem. The United States Department of Agriculture (USDA) nutrient database lists 4,889 foods that contain L-tyrosine. There are 1,962 foods listed that have over $500 \mathrm{mg}$ of L-tyrosine per serving. In reviewing the USDA recommendation, the established serving sizes are small. For example, the serving size for fish or beef is $3 \mathrm{oz}$, which typically contains between $600 \mathrm{mg}$ and $900 \mathrm{mg}$ of L-tyrosine. Most patients eat more than $3 \mathrm{oz}$ of these proteins as a serving. The average meal contains more than $1,500 \mathrm{mg}$ of L-tyrosine. ${ }^{13}$

Complying with the phenelzine prescribing information would induce a significant nutritional deficiency by completely eliminating all tyrosine-containing protein foods.

It is impossible for any human to comply with the phenelzine prescribing information and avoid all L-dopa, L-tryptophan, L-tyrosine, and phenylalanine. Completely eliminating these four amino acids from the human diet would leave no protein-containing food to consume and would induce a significant nutritional deficiency.

\section{Phenelzine tyrosine safety record}

Drug safety is not established by double-blind, placebocontrolled studies. The most reliable safety (side effect) data are collected over time through prescribing to large populations. The earliest peer-reviewed literature located discussing phenelzine, by Saunders et al, ${ }^{4}$ was published on 1 July 1959. Phenelzine has been prescribed for 55 years. There are no documented cases of hypertensive crisis being induced by concomitant administration of L-tyrosine and phenelzine. Until the first case is documented in the literature, there is no scientific basis for asserting in the prescribing information that concomitant administration of L-tyrosine and phenelzine may be a problem.

It appears that the warning regarding L-tyrosine found in the phenelzine prescribing information may have been placed there for a reason other than one that is found in the known scientific literature. When a significant interaction between two administered substances occurs, both substances are required to carry a warning. The US Food and Drug Administration (FDA) considers L-tyrosine ingestion so safe that it does not require it to carry a warning regarding concomitant ingestion with phenelzine. This raises the question of why phenelzine has a tyrosine warning when tyrosine is not required to carry a phenelzine warning.

\section{Current FDA guidelines}

Phenelzine is the subject of ongoing clinical studies under the FDA guidelines. In 2011 the FDA defined the current protocols for ongoing phenelzine drug studies, which address only foods containing tyramine. The FDA places no restriction on L-tyrosine intake in subjects involved in current phenelzine (Nardil) studies. There appears to be a divergence between the phenelzine prescribing information, which originated in the 1950s, and current phenelzine study guidelines. The updated study guidelines have not been reflected in the current prescribing information. ${ }^{14}$

\section{Author experience}

The two primary authors of this paper have a database containing over 3 million patient-days of experience administering L-tyrosine with virtually all prescription drugs. The authors possess L-tyrosine treatment data from over 1,400 medical practices from primarily the US and Canada, as well as many other countries around the world. Administration of MAO inhibitors is uncommon with the exception of southern California. Total phenelzine with L-tyrosine medical record data on file are approximately 43,532 patient-days. This database was started in 1999, and up to the time of this 
writing no concerns have been raised regarding concomitant administration of L-tyrosine with phenelzine. ${ }^{15-29}$

\section{The primary cause of phenelzine- associated hypertensive crisis}

The literature notes numerous documented cases of phenelzine-associated hypertensive crisis. The primary etiology of these events is patient noncompliance with restriction of high-tyramine foods. ${ }^{30-32}$ If a patient experiences a hypertensive crisis while taking phenelzine, the prescribing information offers a protocol to follow. "NARDIL should be discontinued immediately and therapy to lower blood pressure should be instituted immediately". ${ }^{2}$ In a significant number of hypertensive crisis episodes the patient has been noncompliant with the following required restrictions. ${ }^{2}$

Phenelzine prescribing information notes:

Hypertensive crises during NARDIL therapy may also be caused by the ingestion of foods with a high concentration of tyramine or dopamine. Therefore, patients being treated with NARDIL should avoid high protein food that has undergone protein breakdown by aging, fermentation, pickling, smoking, or bacterial contamination. Patients should also avoid cheeses (especially aged varieties), pickled herring, beer, wine, liver, yeast extract (including brewer's yeast in large quantities), dry sausage (including Genoa salami, hard salami, pepperoni, and Lebanon bologna), pods of broad beans (fava beans), and yogurt. Excessive amounts of caffeine and chocolate may also cause hypertensive reactions. ${ }^{2}$

The phenelzine prescribing information takes a position with regard to L-dopa, L-tryptophan, and L-tyrosine and phenylalanine. The formal recommendation found in the prescribing information regarding these four amino acids is "[...] should not take [...]". ${ }^{2}$ Regarding tyramine ingestion, for which there is ample scientific literature supporting the position that ingestion with phenelzine is a problem, a less restrictive warning is noted; "Hypertensive crises during NARDIL therapy may also be caused by the ingestion of foods with a high concentration of tyramine or dopamine. Therefore, patients being treated with NARDIL should avoid high protein food $[\ldots]$ ". ${ }^{2}$ The warning for tyramine appears to be less stringent, despite the fact that according to the literature it is the primary amino acid known to induce hypertensive crisis when ingested with phenelzine.

\section{Conclusion}

Physicians are trained to treat patients in accordance with known science. Intuitively, it may seem that the proper thing to do is place the patient on an L-tyrosine-free diet while administering phenelzine as suggested by the prescribing information. A diet truly free of L-dopa, L-tryptophan, and L-tyrosine and phenylalanine in accordance with phenelzine prescribing information raises concerns relating to nutritional deficiency, a problem that is well documented in the literature. With 55 years of prescribing experience there are no reported cases in the formal scientific literature of L-tyrosine administration with a MAO inhibitor inducing hypertensive crisis. On the contrary, numerous articles exist demonstrating how L-tyrosine actually lowers blood pressure. Although phenelzine prescribing information published years ago asserts that concomitant administration of L-tyrosine with phenelzine is a problem, recent FDA guidelines on phenelzine studies no longer mention or require L-tyrosine considerations to be made when prescribing phenelzine.

The real problem is not the amino acids; it is the drug side effects that may be enhanced with amino acid administration. If the drug were not prescribed, this paper would not have been written.

This article is intended to serve as a literature review, a foundation for opinion formulation, and a reference for future discussion regarding L-tyrosine, phenelzine, and hypertensive crisis.

\section{Disclosure}

$\mathrm{MH}$ discloses his relationship with DBS Labs, Inc., and NeuroResearch Clinics, Inc. The other authors report no conflicts of interest in this work.

\section{References}

1. Dollins AB, Krock LP, Storm WF, Wurtman RJ, Lieberman HR L-tyrosine ameliorates some effects of lower body negative pressure stress. Physiol Behav. 1995;57(2):223-230.

2. $\operatorname{Nardil}^{\circledR}$ (phenelzine) [prescribing information]. New York, USA: Pfizer, Inc. Available from: http://www.pfizer.com/files/products/uspi_nardil. pdf. Accessed June 17, 2014.

3. Kyoto Encyclopedia of Genes and Genomes (KEGG). KEGG tyrosine metabolism homo sapiens reference pathway. Available from: http://www.genome.jp/kegg-bin/show_pathway?org_name=h sa\&mapno $=00350 \&$ mapscale $=\&$ show_description $=$ hide. Accessed June 17, 2104.

4. Saunders JC, Roukema RW, Kline NS, Bailey SD'A, et al. Clinical results with phenelzine. Am J Psychiatry. 1959;116:71-72.

5. Sved AF, Fernstrom JD, Wurtman RJ. L-tyrosine administration reduces blood pressure and enhances brain norepinephrine release in spontaneously hypertensive rats. Proc Natl Acad Sci U S A. 1979;76(7):3511-3514.

6. Deijen J, Orlebeke JF. Effect of L-tyrosine on cognitive function and blood pressure under stress. Brain Res Bull. 1994;33:319-323.

7. Bresnahan MR, Hatzinikolaou P, Brunner HR, Gavras H. Effects of L-tyrosine infusion in normotensive and hypertensive rats. Am J Physiol. 1980;239(2):H206-H211.

8. Ekholm S, Karppanen H. Cardiovascular effects of L-tyrosine in normotensive and hypertensive rats. Eur J Pharmacol. 1987;143(1): 27-34. 
9. Deijen J, Wientjes CJE, Vullinghs HFM, Cloin PA, Langefeld JJ. L-tyrosine improves cognitive performance and reduces blood pressure in cadets after one week of a combat training course. Brain Res Bull. 1999;48(2):203-209.

10. Yamori Y, Fujiwara M, Horie R, Lovenberg W. The hypotensive effect of centrally administered L-tyrosine. Eur J Pharmacol. 1980;68(2): 201-204.

11. Glaeser BS, Melamed E, Growdon JH, Wurtman RJ. Elevation of plasma L-tyrosine after a single oral dose of L-tyrosine. Life Sci. 1979;25(3):265-271.

12. Black J, Waeber B, Bresnahan MR, Gavras I, Gavras H. Blood pressure response to central and/or peripheral inhibition of phenylethanolamine N-methyltransferase in normotensive and hypertensive rats. Circ Res. 1981;49(2):518-524.

13. United States Department of Agriculture (USDA). USDA nutrient database. Available from: http://ndb.nal.usda.gov/ndb/nutrients/report/nutrientsfrm? $\max =25$ \&offset $=0$ \&totCount $=0$ \&nutrient $1=509$ \&nutrient $2=\&$ nutrient $3=$ \&subset=0\&fg=\&sort=f\&measureby=m. Last accessed June 29, 2014.

14. US Food and Drug Administration (FDA). FDA guidance on phenelzine sulfate. Available from: www.fda.gov/downloads/drugs/ guidancecomplianceregulatoryinformation/guidances/ucm209250.pdf. Accessed April 26, 2014.

15. Trachte G, Uncini T, Hinz M. Both stimulatory and inhibitory effects of dietary 5-hydroxytryptophan and tyrosine are found on urinary excretion of serotonin and dopamine in a large human population. Neuropsychiatr Dis Treat. 2009;5:227-235.

16. Hinz M. Depression. In: Kohlstadt I, editor. Food and Nutrients in Disease Management. Boca Raton, FL: CRC Press; 2009:465-481.

17. Hinz M, Stein A, Uncini T. The dual-gate lumen model of renal monoamine transport. Neuropsychiatr Dis Treat. 2010;6:387-392.

18. Hinz M, Stein A, Trachte G, Uncini T. Neurotransmitter testing of the urine: a comprehensive analysis. Open Access J Urol. 2010;2: 177-183.

19. Hinz M, Stein A, Uncini T. A pilot study differentiating recurrent major depression from bipolar disorder cycling on the depressive pole. Neuropsychiatr Dis Treat. 2010;6:741-747.
20. Stein A, Hinz M, Uncini T. Amino acid responsive Crohn's disease: a case study. Clin Exp Gastroenterol. 2010;3:171-177.

21. Hinz M, Stein A, Uncini T. Treatment of attention deficit hyperactivity disorder with monoamine amino acid precursors and organic cation transporter assay interpretation. Neuropsychiatr Dis Treat. 2011;7:31-38.

22. Hinz M, Stein A, Uncini T. Urinary neurotransmitter testing: considerations of spot baseline norepinephrine and epinephrine. Open Access J Urol. 2011;3:19-24.

23. Hinz M, Stein A, Uncini T. Amino acid management of Parkinson disease: a case study. Int J Gen Med. 2011;4:1-10.

24. Hinz M, Stein A, Uncini T. Validity of urinary monoamine assay sales under the "spot baseline urinary neurotransmitter testing marketing model”. Int J Nephrol Renovasc Dis. 2011;4:101-113.

25. Hinz M, Stein A, Uncini T. APRESS: apical regulatory super system, serotonin, and dopamine interaction. Neuropsychiatr Dis Treat. 2011;7:1-7.

26. Hinz M, Stein A, Uncini T. Monoamine depletion by reuptake inhibitors. International Drug, Healthcare and Patient Safety. 2011;3:69-77.

27. Hinz M, Stein A, Uncini T. The discrediting of the monoamine hypothesis. Int J Gen Med. 2012;5:135-142.

28. Hinz M, Stein A, Uncini T. Relative nutritional deficiencies associated with centrally acting monoamines. Int J Gen Med. 2012;5:413-430.

29. Hinz M, Stein A, Uncini T. 5-HTP efficacy and contraindications. Int J Gen Med. 2012;5:413-430.

30. Boulton AA, Cookson B, Paulton R. Hypertensive crisis in a patient on MAOI antidepressants following a meal of beef liver. Can Med Assoc J. 1970;102(13):1394-1395.

31. Horwitz D, Lovenberg W, Engelman K, Sjoerdsma A. Monoamine oxidase inhibitors, tyramine, and cheese. JAMA. 1964;188(13):1108-1110.

32. Shulman KI, Walker SE, MacKenzie S, Knowles S. Dietary restriction, tyramine, and the use of monoamine oxidase inhibitors. J Clin Psychopharmacol. 1989;9(6):397-402.
Clinical Pharmacology: Advances and Applications

\section{Publish your work in this journal}

Clinical Pharmacology: Advances and Applications is an international, peer-reviewed, open access journal publishing original research, reports, reviews and commentaries on all areas of drug experience in humans. The manuscript management system is completely online and includes a very quick and fair peer-review system, which is all easy to use.

\section{Dovepress}

Visit http://www.dovepress.com/testimonials.php to read real quotes from published authors. 